The eastern branch was fainter than the western, and at midnight it was seen from $\gamma$ Virginis, near the horizon, up to Præsepe in the zenith, as a broad and tapering cone of light.

Hence the zodiacal light, when seen in perfection, consists of two cones of light, whose common axis is the Ecliptic, and whose common vertex is a point on that axis almost exactly $180^{\circ}$ from the sun. The fact that the western branch is brighter than the eastern also confirms my idea of its origin, the brighter branch being over the warmer portion of the earth's surface; but I hope to make more observations of its breadth at different times of the year before writing more on this subject.

Jamaica, Feb. 6

MAXWELl Hall

[We hope our correspondent will continue to send us more of his interesting and valuable letters. It is indeed a great gain to science to have an observer stationed on the vantage ground which he occupies. - ED.]

As no one has replied to Maxwell Hall's letter on the zodiacal light (vol, vii. p. 203), I might state that his theory that the earth has two tails which stretch to an indefinite distance away from the sun is not in accordance with observation, for I have often seen the zodiacal light $180^{\circ}$ off the sun. This is no proof against M. H.'s other idea that the two tails curve round and meet; but is there anything in M. H.'s observations contrary to the generally received theory of the zodiacal light? This is that it is not a ring, but a somewhat lens-shaped disc of light, brightest and thickest at its centre (at the sun), and gradually growing thinner and less dense, till it seems to vanish some distance beyond the earth's orbit. Its thickness at its centre would therefore be $60,000,000$ miles, or more, according to M. H.'s observation. The circumstance that he could not see it more than $177^{\circ}$ off the sun might very likely be accounted for by the milky way obscuring it there.

West Hendon House, Sunderland, Feb. 10

\section{The Meteoric Shower}

THE shower of meteors on the night of Nov. 27 last year was evidently well seen in Europe, as I had anticipated, but no notice seems to have been takell of the shower on the night of the 24 th. On that night there was an equally fine display in Jamaica, from about the same radiant point; the night of the $25^{\text {th }}$ was cloudy, and only a few meteors were seen on the vight of the $26 \mathrm{th}$, which was ciear; and the shower on the 27 th was simply a repetition of the shower on the $24^{\text {th }}$; but on both occasions the numbers seen here were somewhat less than in Europe.

These meteors must therefore form two almost distinct bands passing round the sun, which their association with the comet of Biela renders particularly interesting; it is just possible that these two bands intersect, and that one part of the comet belongs to one band and the other part to the other, and that they came into notice and actual contact about the same time in the year 1846 , and of course afterwards separated.

$$
\text { Jamaica, Jan. } 5
$$

MaXivell Hali

\section{Maupertius on the Survival of the Fittest}

Considering that the theories of Darwin and Spencer are among the most important additions ever made to human knowledge, it seems to be a matter of much interest to trace out any occasional glimpses which previous philosophers may have had of the Principles of Natural Selection. In a long note appended by Lord Bolingbroke to his fourth essay concerning Authority in matters of Religion (octavo edition of the Philosophical Works, 1754, vol. ii. p. 253; quarto edition, 1754, vol. iv. p. 255), he reviews a Memoir by Maupertius printed in the History of the Royal Academy of Berlin, for the year 1746. Speaking of the appearances of design, Lord Bolingbroke says :- "Mr. Maupertius proceeds, and admits, but admits, as it were, for argument's sake alone, that the proportion of the different parts and organs of animals to their wants carries a more solid appearance; and he judges that they reason very ili who assert that the uses to which these parts and organs are applied, were not the final causes of them, but that they are so applied because the animal is so made. Chance gave eyes and ears; and since we have them we make use of then to see and hear. He thinks, however, it may be said, that chance having produced an immense number of individuals, those of them whose parts and organs were proportioned to their wants, have subsisted, whilst those who wanted this proportion have perished and disappeared. Those who had no mouth, for instance, could not eat and live; those who wanted the organs of generation could not perpetuate their species; and thus from the present state of things theists draw an argument which will appear falla cious when it is applied to the possible original of things."

I am not aware that notice has been drawn to this distinct allusion to the survival of the fittest. So far as regards the introduction of the notion of chance the statement is no doubt erroneous.

Manchester, Feb. I2

W. Stanley Jevons

\section{"Diathermanous" or "Transfervent"}

THE words "transfervent" and "transfervency" are similar in form to "transparent" and "transparency," and clearly convey their meaning to those who cannot trace them to their source. In number of syllables, also, and in sound are they not more English, or as a Greek might say, less barbarian than words of five, six, or seven syllables which are coined directly from the Greek, but which do not suit so well the Saxon tongue?

W. G. ADAMS

\section{Flight of Projectiles-A Query}

I SHALL feel thankful to any of your numerous mathematical correspondents who will kindly favour me with a simple formuia for determining the deflection in the flight of a leaden cylindroconoidal projectile-the time of flight of which is knowncaused by wind of known force acting at different angles to the vertical plane of the trajectory, with an application of the formula to the following cases. Any other cause of deviation, such as that due to rotation, \&c., may be neglected :-

Suppose the bullet to be $\mathrm{I} \cdot 27$ " long, and its diameler ' $447^{\prime \prime}$, weight $480 \mathrm{grs}$. and the wind to be of force 4 , approximate pressure 4 lbs. per square inch, what is the deviation?

1. When the wind acts at right angles to the trajectory?

2. When it acts at any angle less than a right angle, say $45^{\circ}$ ?

School of Musketry, Hythe, Feb. Io ROBERT REID

\section{ON ACTION AT A DISTANCE*}

WE have now arrived at the great discovery by Örsted of the connection between electricity and magnetism Örsted found that an electric current acts on a magnetic pole, but that it neither attracts it nor repels it, but causes it to move round the current. He expressed this by saying that "the electric conflict acts in a revolving manner."

The most obvious deduction from this new fact was that the action of the current on the magnet is not a push-and-pull force, but a rotatory force, and accordingly many minds were set a-speculating on vortices and streams of æther whirling round the current.

But Ampère, by a combination of mathematical skill with experimental ingenuity, first proved that two electric currents act on one another, and then analysed this action into the resultant of a system of push-and-pull forces be tween the elementary parts of these currents.

The formula of Ampere, however, is of extreme complexity, as compared with Newton's law of gravitation, and many attempts have been made to resolve it into something of greater apparent simplicity.

I have no wish to lead you into a discussion of any of these attempts to improve a mathematical formula. Let us turn to the independent method of investigation employed by Faraday in those researches in electricity and magnetism which have made this institution one of the most venerable shrines of science.

No man ever more conscientiously and systematically laboured to improve all his powers of mind than did Faraday from the very beginning of his scientific career. 
same direction as the electricity of the magnetising current.

It follows from this, by strict dynamical reasoning, that the medium under the action of magnetic force must be in a state of rotation - that is to say, that small portions of the medium, which we may call molecular vortices, are rotating, each on its own axis, the direction of this axis being that of the magnetic force.

Here, then, we have an explanation of the tendency of the lines of magnetic force to spread out laterally and to shorten themselves. It arises from the centrifugal force of the molecular vortices. The mode in which electromotive force acts in starting and stopping the vortices is more abstruse, though it is of course consistent with dynamical principles.

We have thus found that there are several different kinds of work to be done by the electro-magnetic medium if it exists. We have also seen that magnetism has an intimate relation to light, and we know that there is a theory of light which supposes it to consist of the vibrations of a medium. How is this luminiferous medium related to our electro-magnetic medium?

It fortunately happens that electro-magnetic measurements have been made from which we can calculate by dynamical principles the velocity of propagation of small magnetic disturbances in the supposed electro-magnetic medium.

This velocity is very great, from 288 to 314 millions of metres per second, according to different experiments. Now the velocity of light, according to Foucault's experiments, is 298 millions of metres per second. In fact, the different determinations of either velocity differ from each other more than the estimated velocity of light does from the estimated velocity of propagation of small electromagnetic disturbance. But if the luminiferous and the electro-magnetic media occupy the same place, and transmit disturbances with the same velocity, what reason have we to distinguish the one from the other? By considering them as the same, we avoid at least the reproach of filling space twice over with different kinds of xther.

Besides this, the only kind of electro-magnetic disturbance which can be propasated through a non-conducting medium is a disturbance transverse to the direction of propagation, agreeing in this respect with what we know of that disturbance which we call light. Hence, for all we know, light also may be an electro-magnetic disturbance in a non-conducting medium. If we admit this, the electro-magnetic theory of light will agree in every respect with the undulatory theory, and the work of Thomas Young and Fresnel will be established on a firmer basis than ever, when joined with that of Cavendish and Coulomb by the keystone of the combined sciences of light and electricity-Faraday's great discovery of the electromagnetic rotation of light.

The vast interplanetary and interstellar regions will no longer be regarded as waste places in the universe, which the Creator has not seen fit to fill with the symbols of the manifold order of His kingdom. We shall find them to be already full of this wonderful medium; so full, that no human power can remove it from the smallest portion of space, or produce the slightest flaw in its infinite continuity. It extends unbroken from star to star, and when a molecule of hydrogen vibrates in the dogstar, the medium receives the impulses of these vibrations; and after carrying them in its immense bosom for three years, delivers them in due course, regular order, and full tale into the spectroscope of Mr. Huggins, at Tulse Hill.

But the medium has other functions and operations besides bearing light from man to man, and from world to world, and giving evidence of the absolute unity of the metric system of the universe. Its minute parts may have rotatory as well as vibratory motions, and the axes of rotation form those lines of magnetic force which extend in unbroken continuity into regions which no eye has seen, and which by their action on our magnets, are telling us in language not yet interpreted what is going on in the hidden under-world from minute to minute and from century to century.

And these lines must not be regarded as mere mathematical abstractions. They are the directions in which the medium is exerting a tension like that of a rope, or rather like that of our own muscles. The tension of the medium in the direction of the earth's magnetic force is in this country one grain weight on eight square feet. In some of Dr. Joule's experiments, the medium has exerted a tension of 200 lbs. weight per square inch.

But the medium, in virtue of the very same elasticity by which it is able to transmit the undulations of light, is also able to act as a spring. When properly wound up, it exerts a tension, different from the magnetic tension, by which it draws oppositely electrified bodies together, produces effects through the length of telegraph wires, and when of sufficient intensity, leads to the rupture and explosion called lightning.

These are some of the already discovered properties of that which has often been called vacuum, or nothing at all. They enable us to resolve several kinds of action at a distance into actions between contiguous parts of a continuous substance. Whether this resolution is of the nature of explication or complication, I must leave to the metaphysicians.

\section{ON LEAF-ARRANGEMENT*}

A SSUMING, as generally known, the main facts of A Leaf-arrangernent-the division into the whorled and spiral types, and in the latter more especially the establishment of the convergent series of fractions, $\frac{1}{2}, \frac{1}{3}$, $\frac{2}{5}, \frac{3}{3}, \frac{5}{13}, \frac{8}{21}, \frac{13}{34}, \frac{21}{55}, \frac{34}{89}, \frac{55}{14}, \& \mathrm{c}$., as representatives of a corresponding series of spiral leaf-orders among plantswe have to ask what is the meaning that lies hidden in this law?

Mr. Darwin has taught us to regard the different species of plants as descended from some common ancestor ; and therefore we must suppose that the different leaf-orders now existing have been derived by different degrees of modification from some common ancestral leaf-order.

One spiral order may be made to pass into another by a twist of the axis that carries the leaves. This fact indicates the way in which all the spiral orders may have been derived from one original order, namely, by means of different degrees of twist in the axis.

We naturally look to the simplest of existing leaforders, the two ranked alternate order $\frac{1}{2}$, as standing nearest to the original; for it is manifest that the orders at the other extreme of the series, the condensed arrangement of scales on fir-cones, of florets in heads of Compositce, of leaves in close-lying plantains, \&c., are special and highly developed instances, to meet special needs of protection and congregation: they are, without doubt, the latest feat of phyllotactic development; and we may be sure that the course of change has been from the simple to the complex, not the reverse. This point will be illustrated by experiment below.

But first, what are the uses of these orders?-and at what period of the leaf's life does the advantage of leaforder operate? The period must be that at which the leaf-order is most perfect ; not therefore when the twig is mature, with long internodes between the leaves; but while the twig and its leaves are yet in the bud; for it is in the bud (and similar crowded forms) that the leaf-order is in perfection, undisturbed by contortions or inequalities of growth; but, as the bud develops into the twig, the leaves become separated, the stem often gets a twist, the leaf-stalks are curved and wrung to present the blades

* Abstract of paper read by Mr. Hubert Airy, M.A., M.D., before the Royal Society, February 27,1873 . 